\title{
Evaluation of Midwife Health Worker Registration Program Based on the Midwifery Competency Test Using the CIPP Method
}

\author{
Amenda Paswida Sebayang*, SoewartoHardienata, WidodoSunaryo \\ Pakuan University, Bogor, Indonesia
}

*Corresponding Author: Amenda Paswida Sebayang, Pakuan University, Bogor, Indonesia

\begin{abstract}
Indonesian Midwife Competency Test is a process that aims to measure the knowledge and attitudes of health workers following the standards of the midwifery profession. The purpose of this study is to improve the implementation of midwife staff registration programs based on competency tests by evaluating the implementation of midwife health worker registration programs based on competency tests on midwifery alumni in Palembang. The method used is CIPP (Context, Input, Process, Product). Data collection techniques with interviews to test the truth and stability of data and complete the information obtained by observation and documentation. The data analysis technique used was descriptive qualitative, and the interpretation was carried out continuously, repeatedly and consistently until all the data and information that was needed was fulfilled. The results showed that the evaluation of the midwife's health worker registration program based on the overall competency test in Palembang had been carried out properly and according to the procedure. It is expected that the midwife's health worker registration program will continue and be further improved. Evaluation of the Midwife Health Worker Registration Program based on the midwifery competency test using the CIPP method as a whole from the midwife health worker registration program in the city of Palembang has been carried out according to procedures and is excellent. It is hoped that the midwife's health worker registration program will continue and be further developed.
\end{abstract}

Key words: registration of health workers, midwife competency test, CIPP, certification

\section{INTRODUCTION}

Health is a human right and is one of the elements of well-being that must be realized in accordance with the ideals of the Indonesian nation as referred to in the National Principle and the 1945 Constitution of the Republic of Indonesia.

For workers in the health sector, the government applies a policy to carry out a competency test for health workers, including midwives. Competency test is an instrument required by the government to ensure the quality of graduates of health workers. The fundamental objective of conducting competency tests for health tertiary education graduates based on Director General Of Higher Education (2014), among others, is to ensure that competent and nationally standardized tertiary education graduates are health, to test knowledge and skills as a basis for health practice and encourage lifelong learning and as a method assessment for safe and effective management of patients, and also as a benchmark for the success of learning passed by students. This competency test is a process of measuring the knowledge, skills and attitudes of health workers in accordance with professional standards. Competency testing is expected to be a medium to improve the quality of health workers from time to time.

The need for medical personnel for all of Indonesia, around 250 thousand midwives who are considered competent and certified has not been fulfilled. On the other hand, midwifery academy graduates or alumni have exceeded capacity, but have not passed the competency test and are entitled to professional certification. Based on the data it can be seen that the number of midwife alumni who joined Indonesian Midwife Competency Test and was declared not graduating is still relatively large, so that if this situation is left it has the potential to have an impact on the shortage of professional midwives among the community, which in turn has the potential to lead to a decline in health services at the community. 
The legal basis for implementing the competency test is the regulation of the Minister of Health Indonesian Republic no.161 of 2010 concerning the registration of health workers through The Ministry of Health. The Indonesian Health Workers 'Assembly at the central level and the Provincial Health Workers' Assembly are institutions that function to guarantee the quality of health workers. Provincial Health Workers' Assembly conducts competency tests in the regions as part of the registration process. At this stage, the Provincial Health Workers' Assembly functions as an executor of the competency test for health workers. Provincial Health Workers' Assembly itself is a nonstructural provincial level institution and is independent. The function of the competency test in the certification process becomes very important because it will determine the quality of the competency certificate issued as well as the quality of the health worker holding the licence.

As Decree of the Minister of Health number 369 / Ministry of Health / iii / 2007 regarding midwifery professional standards, therein is set a conceptual model and theory underlying midwifery practice, the role of competency functions and the scope of midwifery practice, problem-solving approach methods in conducting midwifery care, namely midwifery management, midwifery service standards, midwifery career development principles are included. Efforts to meet professional competency standards so that midwives can be registered need to be maintained, on the other hand, there is still a large amount of lack of graduation in Indonesian Midwife Competency Test which is one of the requirements for obtaining a professional certificate also needs to be studied further, are there things that can be improved in the competency test process.

\section{LITERATURE REVIEW}

\subsection{The Concept of Evaluation}

According to Alkin (2012), assessment is a systematic investigation or research on the values of an object under study. Operationally, evaluation is the process of describing, summarizing, and reporting information about the benefits of one or several purposes, based on specific assessment criteria, such as quality criteria, worth, probity, equity, feasibility, cost efficiency, safety, and significance.

From the opinions of the experts above, it can be synthesized that evaluation is an activity which includes systematic and continuous measurement and assessment to determine the quality of something, based on specific considerations and criteria in order to make a decision.

\subsection{Definition of midwife competency test}

Competencies as a combination of skills, knowledge, attitudes, values, and abilities that support effective and/or superior performance in professional or work areas, nurses can demonstrate overall competency in their relevant fields through the four steps of competency assessment, namely: 1) knowledge, 2) competencies related to specific tasks, 3) performance, and 4) actions. Matters that underlie these performance-based principles are imperative that competency assessment tools assess problem-solving skills, such as critical thinking skills and apply clinical judgment and reasoning skills (Berg, 2010).

Stufflebeam (2014) explains that the concept of competence in health care is the foundation for quality patient care outcomes; patients expect competent care. The philosophy of competence in nursing deals with the relationship between knowledge, skills, attitudes and clinical judgment by nurses to be able to treat patients safely through evidence-based practice.

Similar to other health workers competency tests, Indonesian Midwife Competency Test is a process that aims to measure the knowledge and attitudes of health workers in accordance with the standards of the midwifery profession. Midwife competence is defined as the ability of midwives to do a task based on knowledge, skills and work attitudes. Midwives who have excellent performance are expected to be able to realize the highest health status - through reducing Infant Mortality (IMR) and decreasing Maternal Mortality (IMR) (Franklin,2015).

\subsection{Program Evaluation Method CIPP(Context, Input, Process And Product)}

According to Corryin (2017), the evaluation method chosen is CIPP (context, input, process and product). The CIPP evaluation model is a comprehensive framework for conducting formative and summative evaluations of programs, projects, personnel, products, organizations, policies, and evaluation systems. Basically, the model provides direction for assessing context (in terms of a 
company's need for correction or improvement); inputs (strategies, operational plans, resources, and agreements to proceed with the required interventions); process (the implementation and intervention costs); and products (positive and negative results of operations).

According to Rajiani (2010), the CIPP model is based on the principle of learning by doing, which is an ongoing effort to identify and correct mistakes made in evaluation practices, to find and test new procedures as needed, and to maintain and combine beneficial methods. The history of model development is a major part and parallel to the development of evaluation models and procedures since the mid-1960s. The CIPP model was developed because the classic evaluation approach of experimental design, goal-based evaluation, peer or expert review site visits, and standardized achievement testing proved to be of limited use, and often did not function and were even counterproductive for evaluating federal programs that emerged in dynamic social contexts and especially the public school district. (Tunc, 2010).

The CIPP evaluation model consists of 4 components which are described as follows:

\section{a. Context Evaluation}

Context evaluation is the basis of assessment which aims to provide reasons for setting goals. Therefore the efforts made by the evaluator at this stage are to give an overview and details about the environment, needs, and objectives. Context evaluation includes analysis of problems related to the program environment or objective conditions that will be carried out. Contains analysis of strengths and weaknesses of particular objects explained that, context evaluation is an attempt to describe and detail the environment of unmet needs, populations and samples served, and project objectives (Gandkomar,2018).

\section{b. Input Evaluation}

The second stage of the CIPP model is evaluation of inputs, or assessments of contributions, which are evaluations aimed at providing information to determine how to use available resources in achieving program objectives. Input evaluation includes personal analysis related to how the use of available resources, alternative strategies that must be considered to complete a program. According to (Gandkomar,2018), evaluation of inputs helps organize decisions, determine available sources, alternatives taken, plans and strategies for achieving goals, and how to work procedures are to achieve them. The input evaluation component includes:

1) Human resources,

2) Supporting facilities and equipment,

3) Funds or budget, and

4) Various procedures and rules needed.

\section{c. Process Evaluation}

Process evaluation is used to detect or predict procedure designs or implementation plans during the implementation phase, provide information for program decisions and as a record or archive of procedures that have taken place. Process evaluation includes the collection of assessment data that has been determined and applied in program implementation practices. Basically, the evaluation process seeks to know the extent to which plans have been implemented and what components need to be improved.

\section{d. Product Evaluation}

Product evaluation is an evaluation measuring the success of achieving goals. Evaluations can also aim at gathering descriptions and assessments of outcomes, and linking them with objectives, contexts, inputs, and processes and to interpreting the feasibility and worth of the program.

Product evaluation is an assessment conducted to see the achievement or success of a program in achieving predetermined goals. At this evaluation stage, evaluators can determine or provide recommendations to the assessed party, whether an application can be continued, developed or modified, or even terminated. 


\section{METHOD}

This research is evaluation research that uses descriptive qualitative methods. The qualitative approach used for evaluation research is a competency-based midwife training program, because both the subject, object and nature of this study have special characteristics that cannot be approached by statistical procedures. The source of the research data were alumni of midwifery students in the city of Palembang who were involved in the implementation of the registration program for health workers based on a competency test. This research was conducted on natural objects, namely the alumni academy in Palembang City. The data source is midwifery alumni in the city of Palembang (Rajiani, 2011).

In this study, researchers used a program evaluation research method with the CIPP model (Context, Input, Process, Product) developed by Aziz (2018), including:

\subsection{Stages of Context Analysis}

Analysis of needs that underlie the midwife's health worker registration program, goals, objectives and policy programs based on midwifery competency tests.

\subsection{Stages of Input Analysis}

Analysis of program activity readiness includes the planning of program activities, procedures and mechanisms, organizational structure, monitoring systems, control of human resource support, infrastructure, and budgets needed in evaluating midwife health worker registration program based on Competency Tests In Midwifery Academy in the city of Palembang.

\subsection{Stages of Process Analysis}

Analysis of the implementation of the program involves the implementation of the program activities program procedures and mechanism of the organizational structure of monitoring and controlling human resource support and infrastructure in the implementation of the midwife health worker registration program based on competency tests in midwifery academy studies in the city of Palembang.

\subsection{Stages of Product Analysis}

Analysis of the results of the health worker registration program based on midwifery competency tests in order to ensure competent and nationally standardized tertiary education graduates. The competency test aims to test skills as a basis for carrying out professionalism in service and encouraging lifelong learning.

\section{RESULTS AND DISCUSSION}

\subsection{The Results of Evaluating the Context Component.}

Findings in the field and information from policymakers stated that the policy regarding the midwife health worker registration program had answered the need for the importance of the midwife health worker registration program where the health workforce registration system is a scoring system designed to identify midwives' ability to carry out their duties through measurement of competency mastery, which is shown in the performance.

Based on the description of the answers from the official informants on the section (section head) of the application of competency tests, the Belmawa Directorate General, The Ministry Of Research, Technology And Tertiary Education, most of the answers stated that the aspects of the needs analysis of the midwife's health worker registration program evaluation program in the city The average Palembang evaluation category are "outstanding", meaning that the evaluation criteria in the needs analysis have reached higher than the desired expectations of the health worker registration program based on midwifery competency tests.

Criteria on the basis of the policy indicate that the registration program for health workers is formulated in accordance with the applicable regulations in the regulation of the Minister of Health of the Republic of Indonesia and meets the legal requirements. Referring to the Directorate General of Higher Education policy, in general, the competency test with national standards as part of a quality assurance system that aims at ensuring patient safety and lifelong learning. 
Based on the description of the answers from the official informants on the section (section head) of the application of competency tests, the Belmawa Directorate General, The Ministry Of Research, Technology And Tertiary Education, most of the answers stated that the aspect of the aim of the midwife's health worker registration program in the city of Palembang was that the assessment category was "good ", It means that the evaluation criteria in the program objectives have exceeded the desired expectations that the targets are clearly formulated to increase the work motivation of educators and the continuity of communication between educators.

The findings in the field state that the target of the health workforce registration program is set based on The Ministry of Health no. 046 of 2013 concerning the registration of health workers where the goal of the registration program for health workers in all health workers who will undertake professional or vocational work. Based on the description of the answers from the official informants at the head of section (section head) of the application of the competency test, the general directorate of Belmawa, The Ministry of Research, Technology and Tertiary Education, most of the answers stated that the target aspects of the midwife's health worker registration program in the average city of assessment categories were " good ", it means that the evaluation criteria in the program targets have exceeded the desired expectations that the program targets are clearly formulated in accordance with the types/grouping of health workers in order to ensure continuity of communication between supervisors and meet the legality provisions of the legislation.

\subsection{Results of the Evaluation of Input Components}

Evaluation of input components of the implementation of the midwife's health worker registration program in the city of Palembang includes strategy, work procedures, organizational structure, resource aspects, infrastructure support, budget support, evaluation monitoring and partnerships.

Based on the description of the answers from the official informants at the head of section (section head) of the application of competency tests, directorate general of Belmawa, The Ministry of Research, Technology and Tertiary Education, most of the answers stated that the strategic aspects and targets of the midwife health worker registration program in the city of Palembang had an average rating category is "outstanding", meaning that the evaluation criteria in the strategy and program targets have reached a higher expectation that the desired strategies and targets are clearly formulated in accordance with the types/grouping of health workers in order to ensure continuity of communication between supervisors and meet the legality requirements of the legislation. Invitation.

Based on the results of the evaluation of work procedure aspects, most of the answers stated that the work procedure aspects of the midwife health worker registration program in the city of Palembang mean that the assessment category was "good", meaning that the evaluation criteria in the program strategy and targets had exceeded the expectations that the desired work procedures were clearly formulated in accordance with types/grouping of health workers in the framework of ensuring the continuity of communication between supervisors and fulfilling the legal requirements of the legislation.

Based on the evaluation results of the organizational structure aspects, most of the answers stated that the organizational structure aspects of the midwife health worker registration program in the city of Palembang mean that the assessment category was "good", meaning that the organizational structure in the program had exceeded the desired expectations that the organizational structure was clearly formulated in accordance with types/grouping of health workers in the framework of ensuring the continuity of communication between supervisors and fulfilling the legal requirements of the legislation.

Based on the evaluation results of the aspects of budget / financial support, the average rating category is "outstanding", meaning that the budget / financial support in the program has reached more than the desired expectations that the budget / financial support is clearly formulated according to the types of needs.

Based on the evaluation results of the partnership aspect, most of the answers stated that the partnership aspect of the registration program for midwife health workers in the city of Palembang was that the evaluation category was "good", meaning that the partnership aspect in the program had 
achieved the desired expectation that the partnership was clearly formulated in accordance with the collaboration.

Based on the evaluation results of the monitoring and evaluation aspects of the answers from the supervisor of competency test, most of the responses stated that the monitoring and evaluation aspects of the midwife health worker registration program in the average city of Palembang were "excellent", meaning that the monitoring and evaluation aspects in the program had reached higher than expected and clearly expected according to implementation.

Based on the results of the evaluation of the organizational aspects of answers from the resource persons of the higher education service institutions in the region ii, most of the answers stated that the organizational aspects of the midwife's health worker registration program in the average city of Palembang were "excellent", meaning that the organizational elements in the program had reached greater than the desired expectations and clearly in accordance with the implementation.

Based on the evaluation of human resources aspects, the answers from the resource persons of the regional higher education service institutions ii, most of the responses stated that the human resource aspects of the midwife's health worker registration program in the city of Palembang mean that the evaluation category was "good" which means the human resource aspect in the program has exceeded the desired expectations according to the needs in carrying out the midwife competency test. Based on the description of the answers from the institutional leadership sources, most of the responses stated that the human resource aspects of the midwife's health worker registration program in the city of Palembang mean that the evaluation category was "good", meaning that the human resource aspect was in accordance with the needs in implementing the midwife competency test.

Based on the results of the evaluation of facilities and infrastructure aspects of the description of the answers from the sources of student affairs of higher education service institutions region II and the leadership of the institution, most of the responses stated that the facilities and infrastructure aspects of the midwife's health worker registration program in the city of Palembang mean the evaluation category was "good" which means aspects facilities and infrastructure in the program have exceeded the expectations yan desired with the needs in the implementation of competency tests for the implementation of competency tests.

\subsection{Process Component Evaluation}

The results based on the evaluation results of the program identification aspect description of the answers from 1 public and 18 private universities in Palembang, most of the responses stated that the identification aspects of the midwife's health worker registration program in the average city of Palembang were "good" ", Meaning that the program identification criteria in the implementation of the health worker registration program have exceeded the desired expectations.

Based on the evaluation results of the scheduling aspect, most of the answers stated that the scheduling aspect of the registration of health workers in the city of Palembang mean that the assessment category was "good", meaning that the scheduling system in the midwife's health worker registration guidance program had exceeded the desired expectations.

The findings in the field state that the assignment aspects of the midwife health worker registration program in the city of Palembang include the division of supervisors and the division of work for lecturers who are able to make work plans for the registration of midwife health workers based on midwifery competency tests with planning and on time. Based on the evaluation results of the assignment aspect, most of the answers stated that the assignment aspect in the midwife health worker registration program in the city of Palembang had an average rating category, meaning that the assignment aspect almost exceeded the desired expectations in guiding alumni to face the midwife competency test.

Findings in the field state that aspects of organizing health worker registration programs in the city of Palembang include work distribution patterns to deliver success and solutions to avoid procedural errors in the preparation of midwife health worker registration documents based on midwifery competency tests. Based on the results of the evaluation of the implementation aspects, most of the answers stated that the implementation aspect of the registration program for midwives' health 
workers in the city of Palembang mean that the assessment category was "good", meaning that the implementation criteria had exceeded the desired expectations.

Findings in the field state that the aspects of the evaluation stage of midwife health workers registration program in the city of Palembang include the unit self-evaluation method. Based on the evaluation results of the evaluation aspects, most of the answers stated that the evaluation aspects of midwife health workers registration program in the city of Palembang were rated very well ", It means that the evaluation criteria in the program evaluation stage have reached more than the desired expectations.

\subsection{Product Component Evaluation Results}

Findings in the field state that the aspects output of the midwife's health worker registration program include the results and perceived benefits of the midwife's health worker registration program. Based on the results of the evaluation of output aspects, most of the answers stated that the aspects output of the midwife's health worker registration program in the city of Palembang mean that the evaluation category was "insufficient", meaning that the evaluation criteria in the output did not exceed the desired expectations.

In the aspect of output, there are some which have not been met, including the implementation system, aspects of human resources, monitoring and evaluation and competency test participants. The implementation system is a factor that affects the output aspect because the implementation system influences the results of the competency test. The aspect of human resources controls output because competency test participants need more intense training questions from educators. Monitoring and evaluation affect output because the results of monitoring and evaluation can be used as a benchmark.

Findings in the field state that the aspects of the outcomes of the health workforce registration program are the directorate general of the ministry of research, technology and higher education who carry out a recapitulation of the value of the competency test results to obtain complete data on the results of the competency test. The recapitulation of the competency test results data is used as the basis for carrying out an analysis of the competency test results. Associated with the provisions on the criteria aspects, of outcomes that the belmawa directorate general of the ministry of technology research and higher education ensures that the competency test program is beneficial for competency test participants in improving performance so as to be able to improve public services, improve the midwife's self-image, and improve the quality of education. Based on the results of the evaluation aspects of outcomes, most of the answers stated that the aspects of outcomes. The registration program for midwife health workers in the city of Palembang means that the assessment category is "insufficient", meaning that the evaluation criteria in the outcomes of the program are considered not to exceed the desired expectations.

In the aspects of outcomes, there are some which have not been met, including the results of the implementation of the registration program for midwife health workers who are still many who have not passed (incompetent), aspects of assignment in terms of making questions and sending questions about institutions that have not done well, correction of the results of the institutional examination has never been involved, and aspects of administration that have not yet been fulfilled.

\section{CONCLuSion}

Evaluation of midwife health worker registration program based on midwifery competency testing using the CIPP method as a whole from the midwife health worker registration program based on midwifery competency testing in the city of Palembang has been carried out according to the procedure and good. It is hoped that the midwife's health worker registration program will continue and be further developed.

The midwife's health worker registration program based on midwifery competency testing aims to measure the knowledge, skills and attitudes of health workers in accordance with the standards of the midwifery profession. Midwife competence is defined as the ability of midwives to do a task based on knowledge, skills and work attitudes. Midwives who have good performance are expected to be able to realize a high degree of health - high through a decrease in Infant Mortality Rate (IMR) and a decrease in Maternal Mortality Rate (MMR). 


\section{REFERENCES}

[1] Alkin, M. C. (Ed.). (2012). Evaluation roots: A broader perspective of theorists' views and influences. Sage Publications.

[2] Aziz, S., Mahmood, M., \&Rehman, Z. (2018). Implementation of the CIPP model for quality evaluation at school level: A case study. Journal of Education and Educational Development, 5(1), 189-206

[3] Berg, R. A., Hemphill, R., Abella, B. S., Aufderheide, T. P., Cave, D. M., Hazinski, M. F.,\&

[4] Bondy, K. N. (1983). Criterion-referenced definitions for rating scales in clinical evaluation. Journal of Nursing Education, 22(9), 376-382.

[5] Coryn, C. L., Wilson, L. N., Westine, C. D., Hobson, K. A., Ozeki, S., Fiekowsky, E. L., ... \&Schröter, D. C. (2017). A decade of research on evaluation: A systematic review of research on evaluation published between 2005 and 2014. American Journal of Evaluation, 38(3), 329-347.

[6] Franklin, N., \& Melville, P. (2015). Competency assessment tools: an exploration of the pedagogical issues facing competency assessment for nurses in the clinical environment. Collegian, 22(1), 25-31.

[7] Gandomkar, R. (2018). Comparing Kirkpatrick's original and new model with the CIPP evaluation model. Journal of Advances in Medical Education \& Professionalism, 6(2), 94-95.

[8] Rajiani, I., \&Jumbri, I. A. (2011). A cultural ecology of new public management in Indonesia. Journal of Administrative Science, 8(1), 17-31.

[9] Rajiani, I. (2010). Applying Personality Traits to Predict Loyalty and Neglect among Employees of Bank Jatim Located in 10 Big Cities of East Java (McCrae's and Hofstede's Theories on effect of Culture to Personality Revisited). JurnalAplikasiManajemen, 8(3), 617-622.

[10] Swor, R. A. (2010). Part 5: adult basic life support: 2010 American Heart Association guidelines for cardiopulmonary resuscitation and emergency cardiovascular care. Circulation, 122(18_suppl_3), S685S705.

[11] Stufflebeam, D.A. and Chris L.S. Coryn. (2014). Evaluation Theory, Model and Applications. San Fransisco, CA: Jossey-Bass

[12] Tunc, F. (2010).Evaluation of an English language teaching program at a public university using the CIPP model. Unpublished Master's Thesis).Middle East Technical University, Ankara.

Citation: Amenda Paswida Sebayang, et.al., "Evaluation of Midwife Health Worker Registration Program Based on the Midwifery Competency Test Using the CIPP Method " International Journal of Managerial Studies and Research (IJMSR), vol 8, no. 7, 2020, pp. 41-48. doi: http:// dx.doi.org/10.20431/23490349.0807005.

Copyright: (C) 2020 Authors. This is an open-access article distributed under the terms of the Creative Commons Attribution License, which permits unrestricted use, distribution, and reproduction in any medium, provided the original author and source are credited. 